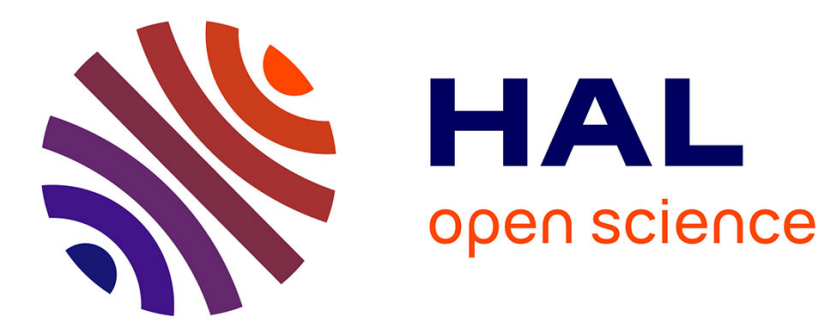

\title{
Variation in the frequency of left-handedness in traditional societies
}

Charlotte Faurie, Wulf Schiefenhövel, Sylvie Le Bomin, Sylvain Billiard, Michel Raymond

\section{- To cite this version:}

Charlotte Faurie, Wulf Schiefenhövel, Sylvie Le Bomin, Sylvain Billiard, Michel Raymond. Variation in the frequency of left-handedness in traditional societies. Current Anthropology, 2005, 46 (1), pp.142-147. 10.1086/427101 . halsde-00184669

\section{HAL Id: halsde-00184669 \\ https://hal.science/halsde-00184669}

Submitted on 31 Oct 2007

HAL is a multi-disciplinary open access archive for the deposit and dissemination of scientific research documents, whether they are published or not. The documents may come from teaching and research institutions in France or abroad, or from public or private research centers.
L'archive ouverte pluridisciplinaire HAL, est destinée au dépôt et à la diffusion de documents scientifiques de niveau recherche, publiés ou non, émanant des établissements d'enseignement et de recherche français ou étrangers, des laboratoires publics ou privés. 


\section{Variation in the Frequency of Left- handedness in Traditional Societies ${ }^{1}$}

\begin{abstract}
CHARLOTTE FAURIE, WULF SCHIEFENHÖVEL, SYLVIE LE BOMIN, SYLVAIN BILLIARD, AND MICHEL RAYMOND Université Montpellier II, CC 065, Place Eugène Bataillon, 34095 Montpellier cedex 5, France (faurie@ isem.univ-montp2.fr) (Faurie)/Institut des Sciences de l'Evolution (CNRS UMR 5554), Montpellier, France (Faurie, Billiard, Raymond)/Max-Planck-Gesellschaft, Human Ethology Group, Andechs, Germany (Schiefenhövel)/Langues, Musiques et Sociétés (CNRS UMR 8099), Villejuif, France (Le Bomin). Io vi o4
\end{abstract}

[Supplementary material appears in the electronic edition of this issue on the journal's web page (http://www.journals.uchicago. edu/CA/home.html).]

The literature on handedness essentially concerns Western or Westernized societies. Some laterality measures are well defined in such societies, among them writing handedness and several indices based on the manipulation of artefacts specific to these cultures (e.g., the Edinburgh Handedness Inventory [Oldfield I97 I], which includes handedness for the use of a toothbrush, a tennis racket, etc.). In preliterate and preindustrial societies opportunities to practice such skills are presumably few (Marchant, McGrew, and Eibl-Eibesfeldt I995), and therefore the existing body of data is mostly irrelevant for the understanding of the evolution of handedness. As do Marchant and McGrew (1998: 226), we think that "such research should encompass a wide array of cultures, focusing especially on traditional societies, particularly those in which Western educational practices have not yet been introduced." In addition, handedness has to be measured for tasks in which individuals are functionally specialized in their own cultures. Finally, the task has to be complex enough for hand preference to be fully and consistently expressed. Therefore hand preference is best assessed for tool manipulation.

The frequency of left-handers has long been believed

(C) 2005 by The Wenner-Gren Foundation for Anthropological Research. All rights reserved o0I I-3204/2005/460I-0008\$10.00

I. We are especially grateful to Hélène Nzé Andou and Ablo Ouattara Boureima for their crucial work as interpreters and informants in the field studies. We thank Anders Møller for many valuable suggestions, Bernard Girard and Jean-Dominique Lebreton for their helpful advice on the statistics of the Eipo study, Thierry Baldet and Elodie Gazave for help in the fieldwork in Burkina Faso, Sylvie Devers for her help in accessing the "Fonds Polaire" from the Museum National d'Histoire Naturelle, and Valérie Durand for bibliographic assistance. Contribution 04.043 of the Institut des Sciences de l'Evolution de Montpellier (CNRS UMR 5554). to be stable across cultures, around Io\% (e.g., Annett I985). Most studies have, however, been conducted in Europe or North America and have dealt with writing handedness, which is often subject to cultural pressures. It is now established that there is substantial geographical variation in this frequency (e.g., Bryden, Ardila, and Ardila I993, Holder and Kateeba 2004, Marchant, McGrew, and Eibl-Eibesfeldt I995, Porac and Coren I98 I, Raymond and Pontier 2004). The study of this variation is of particular interest for an understanding of the evolutionary causes of handedness. Measures of handedness in traditional societies-those not dramatically affected by Western culture through colonization and missionaries-are pivotal for any study of the evolution of manual laterality. Left-handedness frequency is not recorded in ethnographic databases such as the Ethnographic Atlas (Murdock I 967) or the Standard Cross-Cultural Sample (Murdock and White 1969). The best way to assess handedness is to observe individuals spontaneously performing a task (Marchant and McGrew I998), and for this reason field studies are essential. However, traditional societies are rapidly disappearing. The mobile populations of hunter-gatherers that were predominant during the Palaeolithic have almost completely disappeared in recent decades. Similarly, traditional subsistence agriculture, prevalent from the Neolithic to the industrial era, has also sharply declined since the nineteenth century. Fortunately, considerable data are potentially available through the photographs and films of anthropologists who had the opportunity to work in the last traditional societies, before the alterations of living conditions and habits engendered by contact with Western cultures. These data are diverse and have their own biases for the estimation of handedness. Four case studies are considered here: two field studies on traditional societies with a minimum of Westernization (recent and/ or slight changes) and two retrospective studies, based on photographs, on once-traditional societies that are now Westernized.

\section{HANDEDNESS FOR MACHETE USE IN THE BAKA}

The Baka are pygmies and were originally mobile huntergatherers (Lee and Daly I999). However, in the WoleuNtem area of northern Gabon, where they are in close contact with the Fang, traditionally agriculturalists, they have become progressively sub-sedentary during the past decade, and some of them have recently begun to cultivate some crops. The survey was performed on the basis of interviews in the native language of all adult individuals encountered in the five Baka villages of the Woleu-Ntem during one month in 2002. The Baka numbered around 400 at this time. In Baka "left-handed" is kendé and "right-handed" is mokokwabé, "the masculine side." Some Baka even say mokossé (man) for "righthanded" and wossé (woman) for "left-handed." The same analogy exists in several other African languages (Wieschhoff I973). The individuals interviewed (focal) were asked whether they were left- or right-handed for 
TABLE I

Frequency of Left-handers (Percentage) Obtained from Focal Individuals for Themselves and Their Relatives in the Burkina Study

\begin{tabular}{llllll}
\hline & Focal Individuals & Siblings & Offspring & Husbands & Wives or Co-wives \\
\hline Males & $6.90(87)$ & I.47(407) & $5.88(\mathrm{IO} 2)$ & $0.00(34)$ & - \\
Females & $0.00(88)$ & $0.00(24 \mathrm{I})$ & $0.00(76)$ & - & $0.00(94)$ \\
\hline
\end{tabular}

NOTE: Numbers in parentheses are sample sizes.

machete use, and their handedness was recorded as they were seen using machetes in everyday life. They were also asked the handedness of their close relatives (parents, offspring, siblings, and mates). The handedness of individuals who were absent during the study (non-focal) was checked by comparing the reports of the various relatives of theirs who had been interviewed. Children under five were excluded, as handedness may not be stable before this age.

Handedness was assessed for 275 focal individuals and I 28 non-focal individuals. For the latter, the information given by their different relatives was concordant in all cases. For the $49.4 \%$ of initially non-focal individuals who subsequently became focal (I25), the handedness reported by their relatives was concordant in all cases. When hand preference for machete use could be observed in spontaneous activities (68), it was always concordant with reported hand preference. The frequency of lefthanders was $9.52 \%$ among men $(N=\mathrm{I} 89)$ and $10.75 \%$ among women $(N=2 \mathrm{I} 4)$. The sex difference was not significant (Fisher's exact test, $P=0.7$ ).

HANDEDNESS FOR MACHETE USE IN THE BOBODiOULASSO AREA

There are several dozen ethnic groups in the dry savannah around Bobo-Dioulasso, Burkina Faso, living as traditional agriculturalists in permanent villages (Tamisier I998). They use a common language (Dioula) for intergroup communication. The handedness survey was performed in 200I on the basis of interviews in Dioula. The individuals interviewed (focal) were asked whether they were left- or right-handed for machete use (respectively kaghene kamay and kaghene keuri), and their handedness was recorded as they were observed during a manual lateralized task performed during the interview. They were also asked the handedness of their sons, daughters, brothers, and sisters. In addition, a male focal was asked to report the handedness of his wives and a female focal was asked to report the handedness of her husband and co-wives. Individuals aged less than ten years were excluded. When possible, the quality of the information was assessed by crosschecking in two ways, first by checking directly when a relative was later sampled as a focal and second by comparing the frequency of leftand right-handers in the focal sample with that in the kin sample.

Handedness was checked by the observation of spon- taneous manual activities for 3 I.4\% (55) of the 175 focal individuals, and self-reported handedness was concordant with observed handedness in all cases. Among initially non-focal individuals, I.4\% (I 3) were subsequently encountered and handedness could be directly determined (they are therefore included in the focal sample). In all of these cases, the handedness reported by related focal individuals was concordant with observed handedness. The non-focal sample is constituted of 954 individuals.

Table I shows the results obtained in this survey. The general frequency of left-handers obtained for the focal individuals is $3.4 \%$. A sharp discrepancy between the sexes was observed: no left-handed woman was found in the focal sample. The results obtained for the non-focal individuals can be compared with those obtained for the focal, considering the relatedness of individuals. The male frequency of left-handers is $6.9 \%$ for the focal individuals and $5.9 \%$ for their sons. These percentages are not significantly different (Fisher's exact test, $P=0.78$ ). On the contrary, the frequencies obtained for husbands and brothers are very low compared with those for focal males (respectively $P=0.18$ and $P=0.009$ ). These results suggest that the reported handedness of relatives is more reliable for offspring than for siblings or mates. We therefore combined the focal and the offspring samples, and the resulting frequency of left-handers is $6.35 \%$ for men $(N=\mathrm{I} 89)$ and $0 \%$ for women $(N=\mathrm{I} 64)$. This difference is significant (Fisher's exact test, $P=0.0006$ ).

\section{HANDEDNESS FOR BOW SHOOTING IN THE EIPO}

The Eipo live in the Indonesian province of Irian Jaya, recently renamed the Province of Papua (New Guinea). They inhabit approximately $150 \mathrm{~km}^{2}$ of land on the banks of the Eipo River, a rain-forest area. Settlements are found at elevations between $\mathrm{I}, 600$ and 2, $100 \mathrm{~m}$. They numbered close to 800 people in I980, and indications are that the population is growing. They are traditionally horticulturalists. When research was begun in I974, they were using stone, bone, and wooden tools (Schiefenhövel I995). Eipo men (and also some women) wear big earplugs on the side opposite to that of the hand they use for bow shooting (W.S., personal observation during his fieldwork between I974 and I980: during the ceremonies where the young men's ears are pierced, the shooting side is previously explicitly assessed). Handedness for shooting can thus be indirectly observed in photographs 
in which individuals' ears are visible. W.S. has a large collection of around Io,0oo photographs taken during his fieldwork. As the photos analysed were original slides, no picture reversal was possible.

There is just one difficulty with this method. All adult men initially make a hole in only one of their ear lobes. However, when the ear lobe is torn by the weight and size of the earplug, some men use a string to attach the plug in the same ear but some pierce a new hole in the other ear, even though this makes bow shooting more difficult. There are therefore some individuals with the left ear pierced, some with the right ear pierced, and some with both pierced. In the photos, it is not always possible to see both ears of an individual. Consequently, there are seven situations to be analyzed (table 2). In situations 4 and 6 it is impossible to know if the unobserved ear was pierced or not. However, it is possible to estimate the proportion of left-handers with the maximum likelihood method. The following parameters best reflect the underlying biological phenomena: $r$, the probability of initially having the left ear pierced (right-handers), $\mathrm{I}-r$, the probability of having initially the right ear pierced (left-handers); $b$, the probability of having both ears pierced (assumed to be independent of handedness); $p_{1}$, the probability of a pierced ear's being hidden on the photograph; $p_{2}$, the probability of a not-pierced ear's being hidden on the photograph.

We assume that $p_{1}$ and $p_{2}$ are the same for the left and the right ear and that they are independent of handedness. Note that $p_{1}<p_{2}$ : pierced ears are more conspicuous than non-pierced ears, as the earplugs are big and white. Consequently,

$$
\begin{aligned}
& \text { Prob. }(\text { case } \mathrm{I})=b\left(\mathrm{I}-2 p_{1}\right), \\
& \text { Prob. }(\text { case } 2)=r(\mathrm{I}-b)\left(\mathrm{I}-p_{2}-p_{1}\right), \\
& \text { Prob. }(\text { case } 3)=(\mathrm{I}-r)(\mathrm{I}-b)\left(\mathrm{I}-p_{2}-p_{1}\right), \\
& \text { Prob. }(\text { case } 4)=b p_{1}+r(\mathrm{I}-b) p_{2 \prime} \\
& \text { Prob. }(\text { case } 5)=(\mathrm{I}-r)(\mathrm{I}-b) p_{1}, \\
& \text { Prob. }(\text { case } 6)=b p_{1}+(\mathrm{I}-r)(\mathrm{I}-b) p_{3 \prime} \\
& \text { Prob. }(\text { case } 7)=r(\mathrm{I}-b) p_{1} .
\end{aligned}
$$

Because the seven cases are mutually exclusive and represent all possible situations, we can use the maximum likelihood method to estimate $r$. The likelihood is as $\log \mathrm{L}=N_{1} \log \left[b\left(\mathrm{I}-2 p_{1}\right)\right]+N_{2} \log \left[r(\mathrm{I}-b)\left(\mathrm{I}-p_{2}-p_{1}\right)\right]+$ $N_{3} \log \left[(\mathrm{I}-r)(\mathrm{I}-b)\left(\mathrm{I}-p_{2}-p_{1}\right)\right]+N_{4} \log \left[b p_{1}+r(\mathrm{I}-b) p_{2}\right]+$ $N_{5} \log \left[(\mathrm{I}-r)(\mathrm{I}-b) p_{1}\right]+N_{6} \log \left[b p_{1}+(\mathrm{I}-r)(\mathrm{I}-b) p_{2}\right]+$ $N_{7} \log \left[r\left(\mathrm{I}-b \mid p_{1}\right]+\mathrm{CST}\right.$, where $N_{\mathrm{i}}$ is the sample size of case $i$, as described in table 2 . The values of $r, b, p_{1}$, and $p_{2}$ maximizing this function were calculated using Mathematica version 4.0 (Wolfram Research I988-99).

Among all the photos of the collection, I,295 male subjects with at least one ear observable were recorded. Some men may appear in several photos. Because W.S.
TABLE 2

Situations Encountered in Recording Earplugs to Measure Handedness for Bow Shooting in the Eipo Study

\begin{tabular}{lllr}
\hline & \multicolumn{3}{c}{ Ear } \\
\cline { 2 - 4 } Case & Left & Right & Sample Size \\
\hline & & & \\
I & + & + & 10 \\
2 & + & - & 72 \\
3 & - & + & 28 \\
4 & + & n.a. & 743 \\
5 & - & n.a. & 62 \\
6 & n.a. & + & 257 \\
7 & - & - & I 23 \\
\hline
\end{tabular}

NOTE: +, pierced; -, not pierced; n.a., ear not observed.

knows most subjects individually, a sub-sample of 268 photographs was checked, eliminating the cases in which an individual already registered was seen twice or more. The percentage of recounted individuals was $23.1 \%$. However, it is overestimated, as this sub-sample consists of individuals known by W.S., who were overrepresented among the pictures he took himself. Comparing the frequencies of the classes obtained with and without the multiple counts, we can conclude that no bias is generated (Fisher's exact test, $P=0.998$ ). The maximum likelihood estimates are $r=0.7306 ; b=$ $0.0108 ; p_{1}=0.1444 ; p_{2}=0.7776$. The frequency of lefthanders is therefore estimated at $26.9 \%$.

\section{HANDEDNESS FOR TOOL USE IN INUIT}

The Inuit are traditionally mobile hunter-gatherers. Their lands include the northeastern tip of Siberia, the islands of the Bering Sea, the coastal regions of mainland Alaska, the north coast and islands of the Canadian Arctic, and most of the west coast and part of the east coast of Greenland (Tamisier I998). The traditional way of life has now ended for most Inuit. For this study, we used photographs of Inuit from a collection deposited in the Musée de l'Homme (Paris) and photographs published in several books from ethnographic libraries (the Musée de l'Homme and the "Fonds Polaire" of the Museum National d'Histoire Naturelle, Paris), taken between I 892 and I97I. The risk of reversal of the photographs in books is higher than with original slides as used in the Eipo study. However, as left-handers are less frequent than right-handers, and if we suppose that these errors are unbiased (i.e., photos of left-handers are reversed at the same frequency as photos of right-handers), then the frequency of left-handers can only be overestimated.

We considered handedness for unimanual tasks in which the Inuit are specialized in their daily lives. For some actions, handedness could not clearly be determined; in these cases the photo was not considered. The tasks involved manipulation of tools or weapons, such 
as knives, spears, needles, whips, arrow-throwers, and adzes. The results are shown in table 3. A total of 2 I I photographed individuals were available for handedness recording. The frequency of left-handers for knife use was $4.7 \%$ among men $(N=43)$ and $10.5 \%$ among women $(N=$ I 9$)$. The sex difference was not significant (Fisher's exact test, $P=0.6$ ).

The names of the individuals were indicated for 27 photographs. Among them, two individuals were seen performing two different tasks and one three different tasks. Without the name, two individuals were recognized twice in successive photos, wearing the same clothes but performing different manual tasks. In all these cases, the handedness was concordant for the different tasks. However, pooling the data concerning different tasks would be justified only after a demonstration of good inter-task concordance. The frequency of lefthanders obtained would then be $3.3 \%$. The higher prevalence of left-handers among females $(5.4 \%$ vs. $2.2 \%)$ is again not significant (Fisher's exact test, $P=0.4$ ).

\section{DISCUSSION}

The frequency of left-handers seems highly variable in traditional societies. In the four societies considered in the present study, this frequency ranges from $3.3 \%$ to $26.9 \%$. However, possible biases concerning the method used to collect the handedness data have to be considered.

In the Burkina and Gabon studies, the same methods were used in order to facilitate comparison of the results. These studies are based on self-reported handedness. Self-reporting is considered to limit bias; test-retest questionnaires on throwing and hammering handedness in Western societies have produced 100\% concordant responses (Coren and Porac 1978, Raczkowski, Kalat, and Nebes I 974). In our studies, whenever the validity of selfreporting was evaluated by the observation of non-induced lateralized tasks, observed handedness was Iо०\% consistent. Apparently, one's own handedness is confidently known, at least in the traditional societies considered.

These two studies are also partly based on kin-reported handedness. Handedness of other individuals is generally not very well known, even for close kin (e.g., handedness of parents reported by their children [Annett I999]). In the Burkina study, handedness reporting by sibs seems to be of limited reliability. In traditional societies the number of sibs is usually larger (often more than ten and even larger in polygynous families). Mean age difference between sibs is also greater as number of sibs increases, thus reducing the level of intimate interaction. Sibs with different mothers are not necessarily raised together and therefore may not have detailed knowledge of individual characteristics such as handedness. In the Burkina groups studied, polygyny is very frequent. Sibs from the same mother and from different mothers were not distinguished in the survey, and this may well explain the low reliability of sib reporting. In contrast, among the Baka polygyny is rare and disappearing; this could ex-
TABLE 3

Handedness for the Different Tasks in the Inuit Study

\begin{tabular}{|c|c|c|c|}
\hline Task & Right-handers & Left-handers & $\%$ Left-handers \\
\hline \multicolumn{4}{|l|}{ Men } \\
\hline Knife & 4I & 2 & 4.7 \\
\hline Spear & 25 & o & 0 \\
\hline Drum & 39 & I & 2.5 \\
\hline All tasks & I 33 & 3 & 2.2 \\
\hline \multicolumn{4}{|l|}{ Women } \\
\hline Knife & I7 & 2 & I0. 5 \\
\hline Needle & $2 \mathrm{I}$ & 0 & 0 \\
\hline All tasks & 53 & 3 & 5.4 \\
\hline \multicolumn{4}{|l|}{ Both sexes } \\
\hline Knife & 60 & 4 & 6.3 \\
\hline All tasks & 204 & 7 & $3 \cdot 3$ \\
\hline
\end{tabular}

plain why sib reporting seems very reliable. In the Burkina study, the only reliable kin reporting was parents' reporting on the handedness of their children.

In photo studies like those of the Inuit and the Eipo, there is a risk of inversion of the photos. This kind of bias is difficult to detect in photographs from traditional societies because cues such as left-right asymmetries (e.g., written words or letters) are rare or absent. For the Eipo study this bias does not exist, because original slides were examined, but for the Inuit study the proportion of left-handedness may be overestimated (this is because left-handers are the minority in any case, as it is unlikely that most photos were reversed). In some situations it is easy to be sure that an individual is really left-handed: first, when the same picture captures several individuals performing a lateralized task and only one is left-handed (e.g., in Damas I984), and second, when the same landscape is pictured in different photographs, the probability that both photos are reversed being very low (e.g., two photographs from the Ammassalik area, East Greenland, taken in I 906 [Damas I 984:635]). Crosschecking for possible inversion was not possible for all apparent lefthanders. This bias would lead to a frequency of left-handers even lower than the already very low frequency found (around 3\%).

A second risk of bias with photographic databases is the duplication of individuals. Counting the same individual two or more times is possible because individuals cannot always be identified (e.g., the face being hidden) or recognized (e.g., the same individual at different ages). However, these effects can reasonably be supposed independent of laterality. The estimated frequency of left-handers is therefore unaffected, as was shown in the Eipo study. Nevertheless, the overall effect is to increase the sample size and thus reduce the standard error of the estimated frequency. The percentage of duplicates should be estimated to correct the overall sample size. It may be quite high when photographs are taken by a single photographer and are concerned with a single small group located in a restricted geographic area (e.g., 23.I\% in the Eipo study). It is probably lower in other situations such as the Inuit study, in which the photographs were taken at very different times (between I 892 
and I97I) and locations (American Arctic and Greenland). The names of the individuals shown were indicated for $14 \%$ of the photographs, and very few duplicates were found.

A third point needs to be underlined for the Eipo study. Because a cue (the position of the ear plug) is used to measure handedness, the accuracy of the measure depends on the strength of the correlation between this cue and handedness. According to W.S.'s observations, this correlation is very good; before the earlobe of a young man is pierced, he is asked to demonstrate on which side he holds the bow to shoot.

Finally, photo studies do not allow the choice of the task considered for the measure of handedness. In the field studies in the tropics, we chose a tool that played an important role in the everyday life of the people: the machete or its cultural equivalent. For a comparison, we would need to use the same tasks in all the cultures studied. In the Inuit study, the comparison can be made with handedness for knife use, as this tool is quite similar in shape and in functionality. However, for the Eipo study the correlation between handedness for bow shooting and for knife or machete use is unknown. When research was begun in 1974 by W.S., the Eipo were using stone knives, but the number of photos was insufficient to measure the frequency of left-handers for this task.

Despite these methodological problems, the use of photographic archives could be further exploited to investigate the geographical variations of left-handedness frequencies. To our knowledge, the only study of handedness based on the use of photographs is a study of laterality for infant cradling (Damerose and Vauclair 2002). The frequency of left-handedness measured in the present study may not be representative of the frequency prevalent over time in these populations. Recent change in selection pressures due to Westernization may have altered this frequency. However, the Eipo photographs and most of the Inuit photographs were taken before Westernization. The rate of possible change is unknown, as no data are available on the temporal evolution of handedness in traditional societies. For the Baka study, this point is important because the Baka have settled close to Fang villages in the past decade and, as a correlate, the rate of intermarriage has increased (between Baka women and Fang men, the Fang having much higher socio-economic status). The frequency of lefthanders was higher in the Fang than in the Baka (I 4.9\% vs. I0.2 \%, Fisher's exact test, $P<0.047)$. Thus intermarriage may affect the frequency of left-handers among the Baka. Moreover, among the Fang the frequency of left-handers is higher for males than for females (I 7.4\% vs. I 2.6\%, $N=369$ ), and therefore intermarriage may affect the sex difference in handedness in the Baka.

A significant sex difference is observed in the Burkina study: no left-handed women were found, whereas the frequency reached $6.35 \%$ for men. Bryden, Ardila, and Ardila (I993) similarly found no left-handed women for knife use among native Amazonians of Colombia, although the sample size was limited $(N=2 \mathrm{I})$. In the Eipo study the frequency was assessed only for males. In the
Inuit and Baka studies, the frequency of left-handers was slightly higher in females, but the difference was not significant. In Western societies the frequency is generally higher in males (e.g., Annett 1985, Gilbert and Wysocki I992, Hardyck, Goldman, and Petrinovitch I975, McManus 1981). The general assumption of a greater prevalence of left-handers in males is not challenged by the present results, although there is clearly the possibility that in some societies left-handers are equally frequent in the two sexes or even, as suspected by Raymond and Pontier (2004), more frequent in females.

The present study shows the existence of variation in the frequency of left-handers across cultures. Handedness has existed at least since the Upper Pleistocene for Homo neanderthalensis (Bermúdez de Castro, Bromage, and Fernández I988, Lalueza and Frayer 1997) and since the Upper Palaeolithic for H. sapiens (Faurie and Raymond 2004, Groënen I 997). Considering that the handedness polymorphism is probably ancient, many cultures should display frequencies of left-handers above $50 \%$ if the trait is neutral. This is clearly not the case, as no left-handedness frequency above $50 \%$ is reported for any task. The persistence of handedness requires explanation because it is substantially heritable (Francks et al. 2002, McKeever 2000, McManus I99I, Sicotte, Woods, and Mazziotta 1999). Both beneficial and deleterious effects associated with left-handers have been proposed (e.g., Aggleton, Kentridge, and Neave 1993, Annett 1985, Coren and Halpern I99 I, Gangestad and Yeo I997, Gorynia and Egenter 2000, McManus and Bryden I99I, O'Callaghan et al. I987, Raymond et al. I996), and both are required to maintain a polymorphism. The current geographical variation of handedness is an opportunity to identify the selective forces involved through, for example, correlation analyses or experimental studies.

Left-handers have an advantage in sports in which two players confront each other, such as fencing and tennis, but not in non-interactive sports such as bowling (Grouios et al. 2000, Raymond et al. I996). This is explained by a frequency-dependent advantage, left-handers having an advantage when rare because both left- and right-handers are less familiar with this category of competitor. The frequency-dependent advantage of left-handers in interactive sports may have a broader interpretation in the general context of aggressive interaction and warfare. The advantage of being left-handed should be greater in a more violent context. In any given society, the observed frequency of left-handedness should be a balance between its cost and its benefits. Because levels of male/male aggression vary cross-culturally (Daly and Wilson I989), we expect to find a positive correlation across populations between the frequency of left-handedness and the cultural rate of prevalence of face-to-face combat (provided that the cost of left-handedness is constant) (see Faurie and Raymond n.d.). Further work can be expected to provide useful information on how the polymorphism of handedness is maintained in $H$. sapiens. 


\section{References Cited}

AGGLETON, J. P., R. W. KENTRIDGE, AND N. J. NEA VE. I993. Evidence for longevity differences between left handed and right handed men: An archival study of cricketers. Journal of Epidemiology and Community Health 47:206-9.

A N N E T T, M. I985. Left, right, hand, and brain: The right shift theory. London: LEA Publishers.

. I999. Left-handedness as a function of sex, maternal versus paternal inheritance, and report bias. Behavioral Genetics 29:IO3-I4.

BERMÚDEZ DE CASTRO, J. M. T. G. BROMAGE, AND Y. FERNÁNDEZ JALVO. I988. Buccal striations on fossil human anterior teeth: Evidence of handedness in the middle and early Upper Pleistocene. Journal of Human Evolution I7: 4O3-I 2.

BRYDEN, M. P., A. ARDila, AND O. ARDila. I993. Handedness in native Amazonians. Neuropsychologia $3 \mathrm{I}$ : 3OI-8.

COREN, S., AND D. F. HALPERN. I99I. Left-handedness: A marker for decreased survival fitness. Psychological Bulletin I09:90-I06.

COREN, S., AND C. PORAC. I978. The validity and reliability of self-report items for the measurement of lateral preference. British Journal of Psychology 69:207-I I.

DALY, M., AND M. WILson. I989. Homicide. New York: Aldine.

D A M A S, D. Editor. I984. Arctic. (Handbook of North American Indians, vol. 5.) Washington, D.C.: Smithsonian Institution.

DAMEROSE, E., AND J. VAUCLAIR. 2002. "Posture and laterality in human and nonhuman primates: Asymmetries in maternal handling and infant's early motor asymmetries, " in Comparative vertebrate lateralization. Edited by L. J. Rogers and R. Andrew, pp. 306-62. Cambridge: Cambridge University Press.

FAURIE, C., AND M. RAYMOND. 2004. Handedness frequency over more than Io,ooo years. Proceedings of the Royal Society of London B 27I:S43-S45.

n.d. Handedness, homicide, and negative frequency-dependent selection. MS.

FRANCKS, C., S. E. FISHER, I. L. MAC PHIE, A. J. RICHARDSON, A. J. MARLOW, J. F. STEIN, AND A. P. MONACO. 2002. A genomewide linkage screen for relative hand skill in sibling pairs. American Journal of Human Genetics 70:800-805.

GANGESTAD, S. W., AND R. A. YEO. I997. Behavioral genetic variation, adaptation, and maladaptation: An evolutionary perspective. Trends in Cognitive Science I:I03-8.

GILBERT, A. N., AND C. J. WYSOCKI. I992. Hand preference and age in the United States.Neuropsychology 30:60I-8.

GORYNIA, I., AND D. EGENTER. 2000. Intermanual coordination in relation to handedness, familial sinistrality, and lateral preferences. Cortex 36:I-I8.

GROËNEN, M. I997. La latéralisation dans les représentations de mains négatives paléolithiques. Manovre I4:3 I-59.

GROUIOS, G., H. TSORBATZOUDIS, K. ALEXANDRIS, AND V. B ARKOUKIS. 2000. Do left-handed competitors have an innate superiority in sports? Perceptual and Motor Skills 90:I $273-82$.

HARDYCK, C., R. D. GOLDMAN, AND L. F. PETRINOVI T C H. I975. Handedness and sex, race, and age. Human Biology 47:369-75.

HOLDER, M. K., AND D. KATEEBA. 2004. Hand preference survey of 5,I36 school children in Western Uganda. Laterality 9:20I-7.

LALUEZA, C., AND D. W. FRAYER. I997. Non-dietary marks in the anterior dentition of the Krapina Neanderthals. International Journal of Osteoarchaeology 7:I33-49.

LEE, R. B., AND R. DALY. Editors. I999. The Cambridge encyclopedia of hunters and gatherers. Cambridge: Cambridge University Press.

MC KEEVER, W. F. 2000. A new family handedness sample with findings consistent with X-linked transmission. British Journal of Psychology 9I:2 I-39.

MC MANUS, I. C., I98I. Handedness and birth stress. Psychological Medicine I I:485-96.

. I99I. "The inheritance of left-handedness," in Biological asymmetry and handedness. Edited by G. R. Bock and J. Marsh, pp. 25 I-8I. Ciba Foundation Symposium I62. London: Wiley.

MC MANUS, I. C., AND M. P. BRYDEN. I99I. Geschwind's theory of cerebral lateralization: Developing a formal, causal model. Psychological Bulletin i Io:237-53.

MARCHANT, L. F., AND W. C. MC GREW. I998. Human handedness: An ethological perspective. Human Evolution I 3 : $22 \mathrm{I}-28$.

MARCHANT, L. F., W. C. MC GREW, AND I. EIBLEIBESFELDT. I995. Is human handedness universal? Ethological analysis from three traditional cultures. Ethology IOI: 239-58.

MURD OCK, G. P. I967. Ethnographic atlas. Pittsburgh: University of Pittsburgh Press.

MURDOCK, G. P., AND D. R. White. I969. Standard Cross-Cultural Sample. Ethnology 8: 329-69.

O'CALlaghAN, M. J., D. I. TUDEHOPE, A. E. DUGDALE, H. MOHAY, Y. BURNS, AND F. COOK. I987. Handedness in children with birthweights below Iooo g. Lancet I:II 55 .

OLDFIELD, R. C. I97I. The assessment and analysis of handedness: The Edinburgh inventory. Neuropsychology 9:97-I I 3 .

PORAC, C., AND S. COREN. I98I. Lateral preferences and human behavior. New York: Springer Verlag.

RACZKOWSKI, D., J. W. KALAT, AND R. NEBES. I974. Reliability and validity of some handedness questionnaire items. Neuropsychology I 2:43-47.

RAYMOND, M., AND D. PONTIER. 2004. Is there a geographical variation of human handedness? Laterality. In press.

RAYMOND, M., D. PONTIER, A.-B. DUFOUR, AND A. P. M ØLLER. I996. Frequency-dependent maintenance of left handedness in humans. Proceedings of the Royal Society, London B 263:1627-33.

SCHIEFENHÖVEL, W. I995. "Eipo," In Encyclopedia of world cultures: Oceania. Edited by T. E. Hays, pp. 55-59. Boston: G. K. Hall.

SICOTTE, N. L., R. P. WOODS, AND J. P. MAZZIOTTA. I999. Handedness in twins: A meta-analysis. Laterality 4: 265-86.

TAM IS IER, J. C. I998. Dictionnaire des peuples: Sociétés d'Afrique, d'Amérique, d'Asie et d'Océanie. Paris: LarousseBordas.

WiESCHноF, H. A. I973. "Concepts of right and left in African cultures," in Essay on dual symbolic classification: Right and left. Edited by R. Needham, pp. 59-73. Chicago: University of Chicago Press. 